\title{
Affections of Vocal cords and their Management with Video attached Endoscopic Guided Approach than Using Operating Microscope.
}

\author{
Dr. Konide Ravi, Dr. Santhaiah, \\ Prof.HOD ENT department, Guntur Medical college, Guntur.
}

\begin{abstract}
Voice disorders are common to see in ENT Clinical practice., There are so many varieties of vocal cord affections like inflammatory, infectious,Neoplastic, and Neurological .Here are different cases of voice disorders of Benign lesions recorded in ENT Department,Govrnement General Hospital, Guntur Medical college in the annual year of 2012-2014, and their management is different using video attached rigid endoscopic exposure of vocal cords and excision of these lesions with Laparoscopic instruments attached with Diathermy,
\end{abstract}

Key words: Benign Vocal cord lesions, Endoscopic approach, Laparoscopic instruments in laryngeal surgeries.

\section{Introduction;}

The term vocal cord lesions refers to a group of non cancerous (benign), abnormal growths (lesions) within or along the covering of vocal cord. Vocal cords lesions are one the most common causes of voice problems and are generally seen in the three forms;nodules,polyps, and cysts

II. Materials and methods;

The vocal cord lesions come across to ENT OPD the census made were as follows during the 2012-2014.

\begin{tabular}{|c|c|c|c|c|c|c|c|}
\hline $\begin{array}{l}\mathrm{Sr} \\
\mathrm{N} \\
\mathrm{o}\end{array}$ & Type of the lesion & Sex & $\begin{array}{l}\text { Duratio } \\
\mathrm{n}\end{array}$ & $\begin{array}{l}\text { Profess } \\
\text { ion }\end{array}$ & $\begin{array}{l}\text { No } \\
\text { cases } \\
\text { Report } \\
\text { ed }\end{array}$ & Images & \\
\hline 1 & Vocal cord polyp & $\begin{array}{l}\text { Mal } \\
\text { e }\end{array}$ & $\begin{array}{l}24 \\
\text { months }\end{array}$ & $\begin{array}{l}\text { Vendo } \\
\mathrm{r}\end{array}$ & 10 & & $\leftarrow$ \\
\hline 2 & Vocal nodules & $\begin{array}{l}\text { Fem } \\
\text { ale }\end{array}$ & $\begin{array}{l}12 \\
\text { months }\end{array}$ & $\begin{array}{l}\text { Teache } \\
\mathrm{r}\end{array}$ & 20 & & \\
\hline 3 & Vocal cord cysts & $\begin{array}{l}\text { Mal } \\
\mathrm{e}\end{array}$ & $\begin{array}{l}36 \\
\text { months }\end{array}$ & $\begin{array}{l}\text { Agr.La } \\
\text { bourer }\end{array}$ & 10 & & \\
\hline 4 & $\begin{array}{ll}\text { Vocal } & \text { cord } \\
\text { paralysis } & \end{array}$ & $\begin{array}{l}\mathrm{Mal} \\
\mathrm{e}\end{array}$ & $\begin{array}{l}12 \\
\text { months }\end{array}$ & $\begin{array}{l}\text { Busine } \\
\text { ss }\end{array}$ & 10 & & \\
\hline
\end{tabular}




\begin{tabular}{|c|c|c|c|c|c|c|}
\hline 5 & $\begin{array}{ll}\text { Vocal } & \text { cord } \\
\text { papillomas } & \end{array}$ & $\begin{array}{l}\text { Fem } \\
\text { ale }\end{array}$ & $\begin{array}{l}48 \\
\text { months }\end{array}$ & $\begin{array}{l}\text { House } \\
\text { wife }\end{array}$ & 5 & \\
\hline 6 & Leukoplakia & $\begin{array}{l}\text { Mal } \\
\mathrm{e}\end{array}$ & $\begin{array}{l}36 \\
\text { months }\end{array}$ & $\begin{array}{l}\text { Labour } \\
\text { er }\end{array}$ & 10 & $\begin{array}{l}\longleftarrow \leftarrow \\
\leftarrow\end{array}$ \\
\hline 7 & $\begin{array}{l}\text { Haemangioma of } \\
\text { the vocal cord }\end{array}$ & $\begin{array}{l}\text { Mal } \\
\mathrm{e}\end{array}$ & $\begin{array}{l}48 \\
\text { months }\end{array}$ & $\begin{array}{l}\text { Vendo } \\
\text { r }\end{array}$ & 3 & \\
\hline
\end{tabular}

Most of these cases presents to Opd with change in voice with $\mathrm{H} / 0$ voice abuse, tobacco smoking, alcohol consumption, and GERD problems. and these patients profession depends on voice like vendors, teachers, preachers, singers etc. And when we examine these pts either by flexible endoscopy, or Using 70degree endoscopy find out interestingly these lesions which can be documented and explained to the pts the disease process and type of the management. The equipment needed is 1. Storz Endoscopy camera, 2. Rigid 70 degree rod lens nasal endoscope, monitor, video recorder, Suction.

\section{Symptometology;}

presentations of these cases are Vocal fatigue, delayed voice initiations, Low pitched voice, Voice breaks in the first passages of the sentences, Breathy voice, inability to sing in high ,soft voice, increased effort to speak or sing ,Frequent throat clearing, Extra force needed for voice., These pts also presented that symptoms may increase or decrease, in degree, but will persist and do not go away on their own.

\section{Aetiopathology}

Exact cause is not known, They thought to arise following heavy or traumatic use of the voice, including voice misuse such as speaking in an improper pitch, speaking excessively, screaming or yelling, or using the voice excessively while sick .

\section{Diagnosis}

All these pts were requested to come to opd with fasting of 4-6 hrs and $15 \%$ xylocaine sprayed into the oral cavity, and behind the base of the tongue , and pts were examined in sitting position, with head supported by the assistant and ask the pt to wide open the mouth, keeping the tongue outside and held with gauze piece and pass the rigid 70 degree scope behind the base of the tongue, And ask the pt head little flexion and say 'EEEE' and the laryngeal structures can be visualized like Epiglottis, false cords, true cords,arytenoids,postcriciod area, posterior pharyngeal wall. And the movement s of the vocal cords can be assed by asking the to say EEE and with this examination the type of the lesion can be assed plan to treat the lesion also can be judged.

\section{Procedure;}

All these case were admitted and after overnight fasting, were posted under General Anaesthesia,

After induction of General anaestethsia the anaesthesitist requested to put the end tracheal tube of 6.5 or 7 size for adult patients , 4.5 or 5 for children with cuffed, and the rigid endoscope of specially designed with facility to put rigid rod lens of 0 degree nasal endoscope ,passed trans orally and exposed the ;larynx and the epiglottis is gently lifted and exposed the vocal cords and the lesions were exposed and the secretions are gently aspirated and the scope is connected to the carl storz camera and the lesions were nicely seen in to the monitor and the laryngoscope is fixed in that position by suspension device over chest of the pt. And hence surgeons both hands 
are free to do the procedure the lesions were excised with the help of laparoscopy instruments attached with diathermy, successively in toto and send for the biopsy and entire procedures were recorded for documentation.

\section{Results}

A pre op and post op voice were recorded and shown to the pts the difference of the voice change and its improvement. And these cases were discharged and reviewed every monthly for any recurrence; no cases were reported to have recurrence of the disease.

\section{Discussion}

The advantage of the Endoscope attached with camera is precision, avoids more distance of the field, avoids reflection of light over the scope which is inconvient with microscope .

\section{Conclusion}

The presentation of vocal cord lesion though voice change but diagnosis wise these cases were different and we can classify them differently and except for neurological cases all these cases effectively managed surgically with Trans oral video attached rigid endoscopy with using laparoscopy instruments using diathermy.

\section{References}

[1]. Blake Simpson, Clark Rosen, Hans Von Leden, Robert H. Ossoff (2008) Operative Techniques in Laryngology

[2]. Kaypentax, Assessing Dysphonia. Interactive video textbook

[3]. \{ Cummings Otolaryngology: Head and Neck Surgery

[4]. $\quad\{$ Head and Neck Surgery-Otolaryngology (Head \& Neck Surgery)

[5]. \{ Otolaryngology: Head and Neck Surgery--A Clinical \& Reference Guide, Second edition

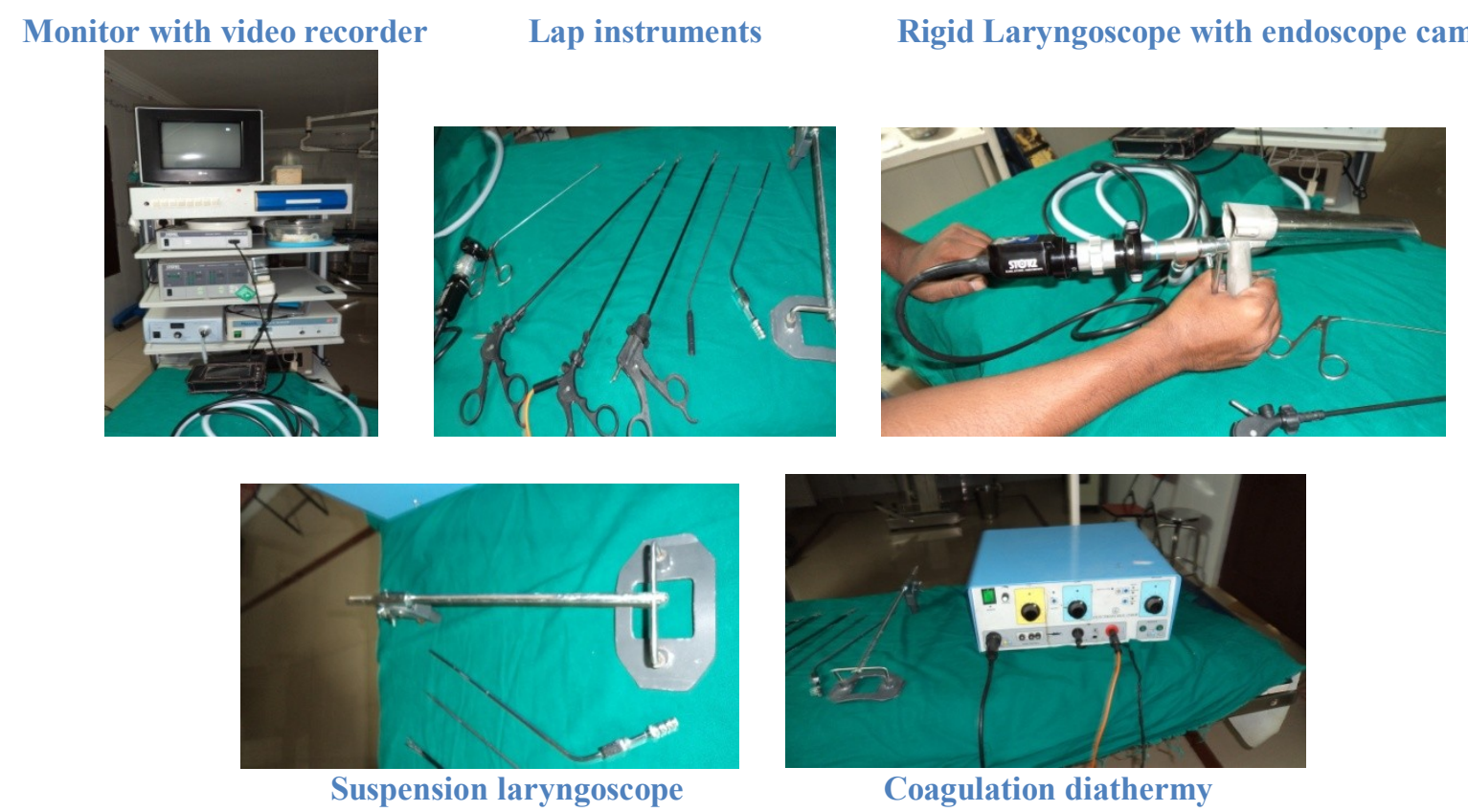

